Child

Publication \#2008-05

\title{
Neighborhood Support and Children's Connectedness
}

\author{
By Britt Wilkenfeld, M.A., Kristin Anderson Moore, Ph.D., and Laura Lippman
}

February 2008

\section{OVERVIEW}

Living in a supportive neighborhood can contribute to the successful development of children and youth. This fact sheet examines whether children living in a supportive neighborhood have an advantage in terms of connections to family, peers, and community. Results indicate that, yes, children who live in highsupport neighborhoods are more likely to have strong connections in other contexts. However, children who live in low-support neighborhoods are less likely to have such connections.

\section{BACKGROUND}

Research has found that varied types of “connectedness" contribute to children's development. For example, children benefit from connections to their:

Neighborhood: Relationships and experiences in the neighborhood influence children's outcomes; specifically, social ties and control among neighbors are related to higher levels of social competence and lower levels of problem behaviors. ${ }^{1}$

Family: Positive parent-child communication, parental involvement, and warm and supportive relationships with parents are associated with lower levels of emotional and behavioral problems, school suspensions, and substance use. ${ }^{2}$

Peers: Feeling positively connected to peers, such as being accepted by friends and being socially competent, is associated with more positive academic outcomes ${ }^{3}$ and fewer behavioral problems. ${ }^{4}$ On the other hand, the negative experience of being rejected by peers and being bullied can lead to withdrawal or aggressive behavior, as well as to poor school performance. ${ }^{5}$
Community: Young people who volunteer are found to have more socially responsible attitudes and to be less likely to engage in problem behaviors than are their peers who do not volunteer. ${ }^{6}$ Connection to a religious community can also facilitate positive development. For example, religious involvement can contribute to better educational and emotional outcomes for adolescents. ${ }^{7}$

Activities: Participation in structured after-school activities like clubs or sports contributes to academic achievement, enhanced social and cognitive skills, positive social behavior, and fewer risky behaviors. ${ }^{8}$ Involvement in such activities facilitates the development of skills and increases exposure to engaged peers and positive adult role models. ${ }^{9}$

\section{Current Analysis}

Are high levels of neighborhood support correlated with connectedness in other contexts? Building on prior research on the connection between the quality of family, peer, and neighborhood contexts, ${ }^{10}$ we used an index of neighborhood support to examine how the perceived level of neighborhood support ${ }^{11}$ was related to children's connectedness in other contexts. In creating this index, we used the following six items from the 2003 National Survey of Children's Health: ${ }^{a}$

My child is safe in our neighborhood;

People in the neighborhood watch out for each other's children;

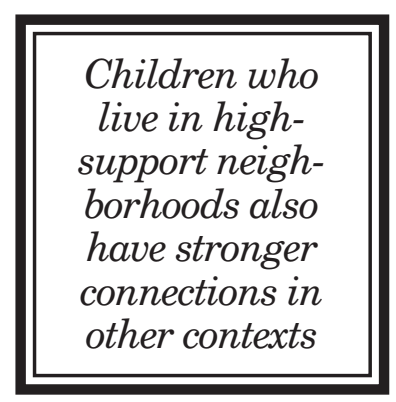

- People in the neighborhood help each other out;

\footnotetext{
a In the original analysis of the Neighborhood Support Index (see Wilkenfeld et al., 2007, for construction), children were classified as living in neighborhoods characterized as most supportive, having moderately high support, having moderately low support, or least supportive. For the current fact sheet, children with parents who perceived their neighborhoods as most supportive or with moderately high support were combined to form the HIGH-support neighborhood group. Children living in neighborhoods perceived as being least supportive or having moderately low support were combined to form the LOW-support neighborhood group. 
There are people I can count on in this neighborhood;

- There are adults nearby who I trust to help my child if he/she got hurt playing outside; and

There are people in the neighborhood who might be a bad influence on my children.

\section{Findings: NeIGHBorhood Support is Consistently Related to ChildRen's ConNeCTEDNEss}

- While causality is complex, the table below indicates that every measure of connectedness is higher for children living in high-support neighborhoods than for children living in low-support neighborhoods.

- Children who live in high-support neighborhoods are more likely than children living in low-support neighborhoods to have discussions with their parents, to have parents who attend their events and meet their friends, to exhibit social competence with peers, to attend weekly religious services, and to participate in a variety of after-school activities.

- The largest differences in connectedness by level of neighborhood support are found for family conflict resolution and children's participation in after-school activities. For example, 62 percent of children living in high-support neighborhoods participated in sports activities in the past 12 months, compared with 47 percent of children living in low-support neighborhoods.

The differences between children from high- and low-support neighborhoods are less pronounced for other activities, including attending weekly religious services and less-frequent television watching. Nevertheless, children living in high-support neighborhoods are more likely to have these experiences.

- Additional analyses (not shown) find that children who live in high-support neighborhoods have higher odds of being connected to family, peers, and the larger community, even after taking into account characteristics of parents' backgrounds, including race, education, poverty level, and family structure. ${ }^{\mathrm{b}}$

\begin{tabular}{|c|c|c|}
\hline \multicolumn{3}{|c|}{ CHILDREN’s Connectedness BASED ON LEVEL OF NEIGHBORHOOD SuPPORT } \\
\hline Connection to Family & $\begin{array}{l}\text { High-Support } \\
\text { Neighborhood }\end{array}$ & $\begin{array}{l}\text { Low-Support } \\
\text { Neighborhood }\end{array}$ \\
\hline Parent and child easily discuss important issues & $77 \%$ & $69 \%$ \\
\hline Family disagreements are usually/always discussed in a calm manner & $74 \%$ & $62 \%$ \\
\hline Parent usually/always attends child's events or activities & $82 \%$ & $69 \%$ \\
\hline Parent has met all or most of child's friends & $85 \%$ & $71 \%$ \\
\hline \multicolumn{3}{|l|}{ Connection to Peers } \\
\hline Child usually/always tries to resolve conflicts with friends and family & $71 \%$ & $56 \%$ \\
\hline Child usually/always gets along well with others & $92 \%$ & $83 \%$ \\
\hline Child never bullies or is mean to others & $78 \%$ & $68 \%$ \\
\hline Parent is not concerned about child being bullied by other children & $68 \%$ & $55 \%$ \\
\hline \multicolumn{3}{|l|}{ Connection to Community } \\
\hline Child volunteered at school, church, or in the community (in past 12 months) & $64 \%$ & $49 \%$ \\
\hline Child attends religious services on a weekly basis & $57 \%$ & $50 \%$ \\
\hline \multicolumn{3}{|l|}{ Connections Through Activities } \\
\hline Child spends less than one hour a day watching television & $25 \%$ & $18 \%$ \\
\hline Child participated in sports after school or on weekends (in past 12 months) & $62 \%$ & $47 \%$ \\
\hline $\begin{array}{l}\text { Child participated in clubs or organizations after school or on weekends } \\
\text { (in past } 12 \text { months) }\end{array}$ & $56 \%$ & $45 \%$ \\
\hline
\end{tabular}

Note: All differences between children in high- and low-support neighborhoods are statistically significant $(\mathrm{p}<.001)$. 


\section{Conclusion}

Children benefit from positive connections to parents, peers, the community, and other societal institutions. This fact sheet presents evidence showing that neighborhood connectedness is related to being connected in other ways as well. The good news is that connections can be compounding; that is, connections in the neighborhood may foster developing relationships in other contexts and participating in structured activities. (Of course, causality probably goes in both directions, from family to neighborhood as well as from neighborhood to family.) The bad news is that children who are already at a disadvantage, by living in a low-support neighborhood, are less likely to have opportunities to form important connections in other contexts.

Note: All estimates are based on data from the National Survey of Children's Health, 2003, sponsored by the Maternal and Child Health Bureau, U. S. Department of Health and Human Services.

1 Elliott, D. S., Wilson, W. J., Huizinga, D., Sampson, R. J., Elliott, A., \& Rankin, B. (1996). The effects of neighborhood disadvantage on adolescent development. Journal of Research in Crime and Delinquency, 33(4), 389-426.

2 Moore, K. A., Chalk, R., Scarpa, J., \& Vandivere, S. (August 2002). Family strengths: Often overlooked, but real (Research Brief). Washington, DC: Child Trends.

3 Malecki, C. K., \& Elliot, S. N. (2002). Children's social behaviors as predictors of academic achievement: A longitudinal analysis. School Psychology Quarterly, 17(1), 1-23.

4 Manz, P. H., Fantuzzo, J. W., \& McDermott, P. A. (1999). The parent version of the preschool social skills rating scale: An analysis of its use with low-income, ethnic minority children. School Psychology Review, 28(3), 493-504.

5 Rubin, K. H., Coplan, R. J., Chen, X., Buskirk, A. A., \& Wojslawowicz, J. C. (2005). Peer relationships in childhood. In M. H. Bornstein \& M. E. Lamb (Eds.), Developmental Science (pp. 469-512). Mahwah, NJ: Lawrence Erlbaum Associates.

6 Zaff, J. F., \& Michelsen, E. (October 2002). Encouraging civic engagement: How teens are (or are not) becoming responsible citizens (Research Brief). Washington, DC: Child Trends.

${ }^{7}$ Regnerus, M. D. (2003). Religion and positive adolescent outcomes: A review of research and theory. Review of Religious Research, 44(4), 394-413.

8 Eccles, J. S., Barber, B. L., Stone, M., \& Hunt, J. (2003). Extracurricular activities and adolescent development. Journal of Social Issues, 59(4), 865-889.

9 Zaff, J. F., Moore, K. A., Papillo, A. R., \& Williams, S. (2003). Implications of extracurricular activity participation during adolescence on positive outcomes. Journal of Adolescent Research, 18(6), 599-630.

10 Cook, T. D., Herman, M. R., Phillips, M., \& Settersten, R. A. (2002). Some ways in which neighborhoods, nuclear families, friendship groups, and schools jointly affect changes in early adolescent development. Child Development, 73(4), 1283-1309.

${ }^{11}$ Wilkenfeld, B., Lippman, L., \& Moore, K. A. (September 2007). Neighborhood Support Index (Fact Sheet). Washington, DC: Child Trends. 